\title{
REDUCTION IN OPIATE ACTIVATION AFTER CHRONIC ELECTRO- CONVULSIVE SHOCK - POSSIBLE ROLE FOR ENDORPHINS IN THE BEHAVIORAL EFFECTS OF CONVULSIVE SHOCK TREATMENT
}

\section{R.J. KATZ and K. SCHMALTZ}

Mental Health Research Institute, Department of Psychiatry, University of Michigan Medical Center, Ann Arbor, MI 48109 (U.S.A.)

(Received Aprll 21st, 1980)

(Revised version received May 19th, 1980)

(Accepted May 20th, 1980)

SUMMARY

Group-housed adult male Sprague-Dawley rats were given a series of 4 exposures to electroconvulsive shock therapy or equivalent handling without shock (sham treatment). Twenty-four hours after the final treatment the rats were given vehicle or one of two doses of morphine intraperitoneally, and motor activity was assessed by remote sensing for $60 \mathrm{~min}$. A significant shift of the normal dose-response curve towards the right was seen after electroshock. This may point to cross-tolerance between electroshock and opiates upon this behavioral measure. The results are consistent with the hypothesis that endorphins may mediate certain aspects of electroshock.

Electroconvulsive shock therapy (ECT) is one of the most effective of somatic therapies for endogenous depression and certain subtypes of schizophrenia [4]. It remains a therapy of choice for otherwise refractory cases of severe psychopathology, especially long-standing but pharmacotherapeutically resistant depressions [4]. The underlying psychobiological mechanisms through which ECT exerts its therapeutic effects are not established, although biogenic amines have been hypothesized to play a critical role $[3-5,11]$. Recently it has been suggested that endogenous opioid neuropeptides may also be involved in many of the physiological and behavioral changes brought about by ECT. Several lines of evidence support this view. Clinically, ECT has some established analgesic properties in cases of chronic pain [11, 13]. Preclinically, ECT induces opiate-like changes in respiration, 
thermoregulation, pain sensitivity and catalepsy, all of which are attenuated by the post-synaptic blocker naloxone [1, 2].

Selected doses of opiates, particularly lower doses, are also known to produce an increase in locomotor activity [7]. Since ECT itself produces a state of opiate-like catalepsy, and since this effect is more typical of higher degrees of opiate stimulation, it is difficult to directly assess whether ECT has any effects related to the lower-dose opiate-elicited activation effect. One possible means of further evaluating this issue, however, is to examine the cross-tolerance of ECT and morphine with respect to drug-induced activity. It is possible that pretreatment with ECT might produce behavioral tolerance to the activating effects of morphine similar to those produced by morphine itself. This was examined in the present investigation.

Eighty-four adult ( 70 day) male Sprague-Dawley rats $(n=12 /$ cell, Charles River Farms) were group housed with food (Teklad 4.0\% fat diet S-0836) and tap water continuously available and $12 \mathrm{~h} / 12 \mathrm{~h}$ lighting cycles (lights on at $07.00-19.00 \mathrm{~h}$ ).

Motor activity was monitored upon commercially available tuned oscillators (Stoelting, Chicago) which have been described in detail in previous publications [8, 9]. Rats were individually placed in $50 \times 40 \times 22 \mathrm{~cm}$ polypropylene containers containing fresh pine-chip bedding which rested upon the platforms.

Rats received 4 ECT exposures or exposure to all procedures with the exception of passage of convulsive current (sham ECT). ECT parameters were: $0.2 \mathrm{sec}$ of $60 \mathrm{~Hz}$ current at $400 \mathrm{~V}$. Testing began $24-48 \mathrm{~h}$ after the final ECT or sham ECT exposure. Rats were individually habituated for $4 \mathrm{~h}$, then briefly removed and injected, 1 $\mathrm{ml} / \mathrm{kg}$, intraperitoneally with vehicle or one of two doses of morphine sulfate. Activity was then recorded for $1 \mathrm{~h}$ in 10-min blocks. A separate group of 12 rats was injected with $10 \mathrm{mg} / \mathrm{kg} /$ day of morphine for the 4-day period and tested as described above, and similarly tested $24-48 \mathrm{~h}$ after the last injection. This was a direct control for the demonstration of reliable cross-tolerance effects within the drug condition.

All data are presented as means and standard deviations. Statistical analysis was by 3 -factor analysis of variance, the factors being ECT vs sham, drug dosage $(0.00$, $0.75,1.50 \mathrm{mg} / \mathrm{kg}$ ) and time (minutes $0-60$ ). The last factor was corrected for repeated measures.

Vehicle injections occasionally produced an acute activation lasting less than 10 min. In contrast to vehicle, morphine injection was followed by a graded longlasting behavioral activation which was present for most of the testing interval. The normal degree of opiate activation was blunted by ECT. These findings were confirmed as statistically reliable beyond chance levels. Main effects of electroshock $(F=55.6 ; \mathrm{df}=1,67)$ and $\mathrm{drug}(F=14.2 ; \mathrm{df}=3,67)$ were both significant $(P<$ $0.0001)$; however, the effect of time $(F=0.5$; df $=3,345)$ was not. Interactions of ECT and drug $(F=4.7 ; \mathrm{df}=2,67)$, time and drug $(F=1.9 ; \mathrm{df}=10,345)$, time and $\operatorname{ECT}(F=4.3 ; \mathrm{df}=5,345)$ and 3 factors $(F=2.4 ; \mathrm{df}=10,345)$ were all 
significant below a $P<0.05$ criterion. The chronic (i.e. $10 \mathrm{mg} / \mathrm{kg} \times 4$ ) morphinetreated rats showed no activation effect to either test dose of morphine: mean $-1 \mathrm{~h}$ score (+ S.D.) for 0.75 and $1.5 \mathrm{mg} / \mathrm{kg}$ injected groups were $205 \pm 47$ and $193 \pm$ 32. Vehicle-treated rats scores were $48 \pm 29(F<1$ no reliable differences from vehicle). Thus tolerance was demonstrated to the activating effects of morphine and cross-tolerance of ECT and morphine was also shown.

The facts that ECT and drug administration both had reliable effects, and that they interacted in a statistically reliable manner, support the hypothesis that ECT affected the normal response to an opiate drug. These findings are consistent with the view that ECT exerts some of its effects through the release of endorphins, although this does not rule out the previously established contributions of other transmitter systems.

One logical extension of an endorphin-mediated theory of ECT's psychobiological mode of action is that depression may involve hypofunctions of endogenous opioid neuropeptides. Such a view is consistent with the theoretical positions of other researchers [10] and with the observed clinical manifestations of affective disorders such as heightened pain and reduced pleasure. Depression may be a more complex phenomenon than can be accounted for by a single neurotransmitter malfunction, and the present hypothesis is not intended as an exclusive but rather a supplementary explanation of certain aspects of ECT and of depression.

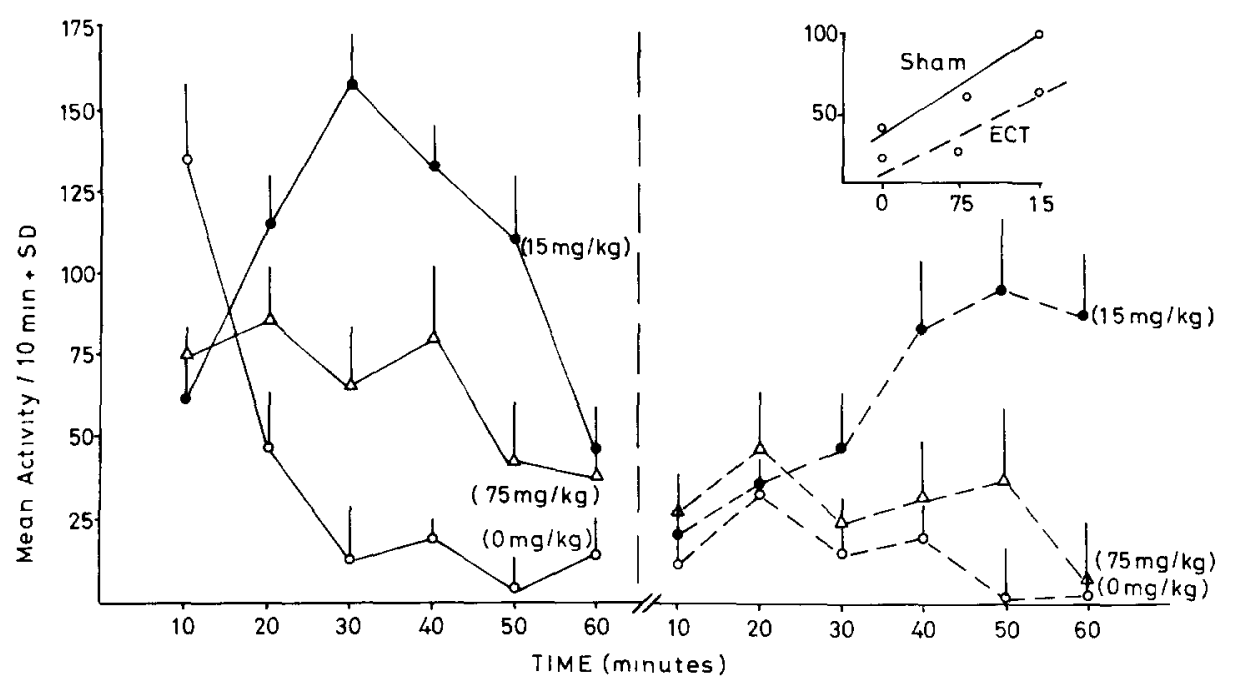

Fig 1. Effects of sham treatment vs electroconvulsıve shock on behavioral activation to opiates in the rat. Solid lines are sham rats; broken lines are ECT-pretreated rats. All rats were administered 4 control or shock treatments, then tested for responses to vehicle or morphine. A $4 \mathrm{~h}$ habituation preceded drug injection. Motor activity is presented as mean and standard deviation Insert in upper right indicates mean 10 min scores across blocks, and demonstrates the shift to the right 
In closing, it must be noted that these findings, although consistent with the hypothesized release of endogenous opioid neuropeptides by ECT, do not exclude additional effects by other neurotransmitters. Nor do they argue that the sole mediation of ECT's effects (including the reported tolerance effect) is exclusively opioid. Biogenic amines may play significant roles in tolerance development, including opioid tolerance. Finally, although endogenous opioids may be released, any therapeutic implications must also be viewed in the light of the reported tolerance effect. Development of tolerance argues that the functional significance of electroshock-induced release may be concomitantly reduced. This indeed would argue against a strict endorphin hypofunction in depression. Both these findings and their qualifications suggest that additional tests of the functional significance of endogenous opiates in depressive syndromes should be considered.

\section{ACKNOWLEDGEMENTS}

Supported by Grant MH 31588-01 to Drs. B.J. Carroll (chief investigator) and R.J. Katz (co-investigator). Parts of this work were carried out by the second author in partial fulfillment of an undergraduate honors requirement. The statistical assistance of R.C. Shea and editorial assistance of Abe Feingold are acknowledged with gratitude.

\section{REFERENCES}

1 Belenky, G L and Holaday, J W, The opıate antagonist naloxone modifies the effect of electroconvulsıve shock (ECS) on respiration blood pressure and heart rate, Brain Res., 177 (1979) 414-417

2 Belenky, G L and Holaday, J W., Electroconvulsive shock (ECS) in rats: naloxone modification of post ECS behaviors provides evidence for functional endorphin release In E.L Way (Ed.), Endogenous and Exogenous Opiate Agonists and Antagonısts, Pergamon, New York, 1980, pp. 487-490

3 Ebert, M H , Baldessarını, R J., Lıpınskı, J.F and Berv, K., Effects of electroconvulsıve seizures on amine metabolısm in rat bran, Arch gen. Psychiat., 29 (1973) 397-401.

4 Fink, M, Convulsive Therapy, Theory and Practise, Raven Press, New York, 1979

5 Grahame-Smith, D G., Green, A.R. and Costain, D W., Mechanısms of action of the antidepressant action of electro convulsive shock therapy, Lancet, (1978) 254-256.

6 Hong, J.S , Gilhn, J C , Yang, H -Y.T and Costa, E, Repeated electroconvulsive shocks and the brain content of endorphins, Brain Res, 177 (1979) 273-278

7 Iwamoto, E.T, Opiold induced hypermotility in rats In E L. Way (Ed), Endogenous and Exogenous Opıate Agonısts and Antagonısts, Pergamon, New York, 1980, pp 155-158

$8 \mathrm{Katz}, \mathrm{R} \mathrm{J}$, Hypophysectomy and the structure of exploratory behavior in the rat, Behav neural Biol , 27 (1979) 227-232

9 Katz, R J and Carroll, B.J., Endocrine control of psychomotor activity in the rat: effects of chronic dexamethasone upon general activity, Physiol. Behav., 20 (1978) 25-30.

10 Klnne, N S , L1, C H., Lehmann, H.E , Lastha, A , Lask1, E and Cooper, T., 3-Endorphin induced change in schizophrenic and depressed patıents, Arch gen Psychıat, 34 (1977) 1111-1113

11 Mandel, M.R., Electroconvulsıve theory for chronic pain associated with depression, Amer J Psychıat., 132 (1975) 632-636.

12 Modigh, K., Long term effects of electroconvulsive shock therapy on synthesis and turnover of brain monoamines, Psychopharmacology, 44 (1976) 179-185

13 Von Hagen, K O., Chronic intolerable pain - discussion of its mechanism and report of eight cases treated with electroshock, J Amer. med. Assoc, 165 (1957) 773-777. 